\section{BRITISH DENTAL ASSOCIATION (THE 'COMPANY') (REGISTERED IN ENGLAND AND WALES WITH COMPANY NUMBER 14161)}

\section{ANNUAL GENERAL MEETING}

NOTICE IS HEREBY GIVEN that the Annual General Meeting of the British Dental Association will be held at 9.30 am on Thursday 26 May 2016 in the Exchange Auditorium of the Manchester Central Convention Complex, Petersfield, M2 3GX, for transaction of the following business:

1. To receive and consider the audited accounts for the financial year ended 30 September 2015 including the Directors' and auditors' reports, as included in the 8 April 2016 edition of the British Dental Journal

2. To reappoint BDO Stoy Hayward, LLP ('BDO') as the company's auditors to hold office until the next Annual General Meeting and to authorise the Directors to fix their remuneration

3. That Dr Peter Dyer be elected President for 2017-2018

4. To consider and, if thought fit, approve (on recommendation of the Principal Executive Committee), changes in the Articles of Association as set out in Appendix A

5. That the 2017 Annual General Meeting be held on Thursday 25 May 2017 at the Manchester Central Convention Complex.

DATED 8 April 2016

BY ORDER OF THE PRINCIPAL EXECUTIVE COMMITTEE

Registered Office:

64 Wimpole Street, London, W1G 8YS

NOTE: A member entitled to attend, speak and vote at the Meeting is entitled to appoint a proxy who need not be a member to attend and exercise all or any of his rights at the meeting.

\section{Appendix A}

That the Articles of Association be amended as follows:

That in Article 16 (C), remove the words 'If, by notice in writing to the Chief Executive of the Association, he resigns from membership of the Association. Provided that, except with the consent of the Principal Executive Committee, a Member shall not have the right to resign from membership whilst any subscriptions or other moneys shall be owing from him to the Association' and insert in their place 'If he resigns from membership of the Association. For a resignation to be effective it must be made either (1) in writing or (2) by electronic communication or (3) orally. The resignation shall be effective upon receipt of any of the aforesaid communications by the Chief Executive, or a BDA member of staff designated by the Chief Executive to act on his behalf for this purpose, and subject to any terms and conditions of membership'

\section{BOOK REVIEW}

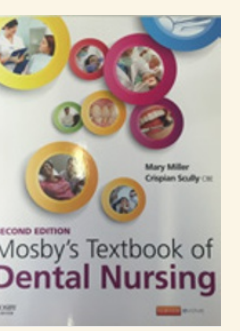

\section{MOSBY'S TEXTBOOK OF DENTAL NURSING,} SECOND EDITION

Mary Miller and Crispian Scully

Elsevier

price $€ 34.99$ pp 464

ISBN 9780702062377

This textbook is easy to read and navigate through. It is clearly divided into broad sections covering topics from chairside dental care to relevant legislation and standards. Important facts are laid out in 'Key Points' boxes and crucial definitions are outlined. There are also 'Find out more' areas that highlight resources (such as website links to guidelines and articles) should the reader wish to further their knowledge. The 'Identify and Learn' sections have some appeal as they encourage the reader to study and relate to their surroundings. Examples include identifying a local NHS dentist that patients can register with, or recognising specific materials used in practice.

The content itself is largely well written, offering depth and background to the reader. In the anatomy and charting sections, the use of clearly described and labelled images effectively complements the text. Consequently, traditionally challenging topics are made more comprehensible.

As the second edition, this updated version includes various additions, most notably information on the appropriate use of social media. Given the widespread use of multiple social media outlets, advice on how to avoid litigation and ensure proper conduct 'online' in accordance with the GDC standards is a smart and relevant inclusion.

For student dental nurses preparing to sit for examinations, the textbook seems to be a good source of revision. Similar to many textbooks, there is the option to download an image bank and practice multiple choice questions (MCQs) from the accompanying website, to help test and consolidate knowledge.

The reader must be aware that the textbook follows the National Examining Board for Dental Nurses (NEBDN) and is aligned with their qualification requirements. Different institutions may suggest students use other publications thus it is important to liaise with relevant staff. It is also wise to flick through this textbook in order to familiarise yourself and determine whether the style is suited to you.

Overall, the textbook adopts a holistic approach to patient care. Delivery of relevant legislative and regulatory information is well considered and appropriate emphasis has also been placed on ethical and professional practice.

N. DOSHI

\section{UNSCHEDULED DENTAL CARE EVENT HELD IN MANCHESTER}

On 10 February an Unscheduled Dental Care event was held in Manchester, supplementing a previous event held in London on 18 November 2015.

A series of presentations were given focussed on planning local unscheduled dental care services and the experiences encountered from a clinician's perspective. Table discussions provided an opportunity for views to be heard on the various components contributing towards unscheduled dental care services. It was clear that services varied, and that there is room for improvement in the delivery and scope of the service with more robust models and information sharing needed to help develop tailored and appropriate provision.

The information from both the London and Manchester events are being compiled into a report which will inform the Unscheduled Dental Care Review and a subsequent Commissioning guide. For further details and to get involved interested readers are invited to email abasra@kss.hee.nhs.uk. 